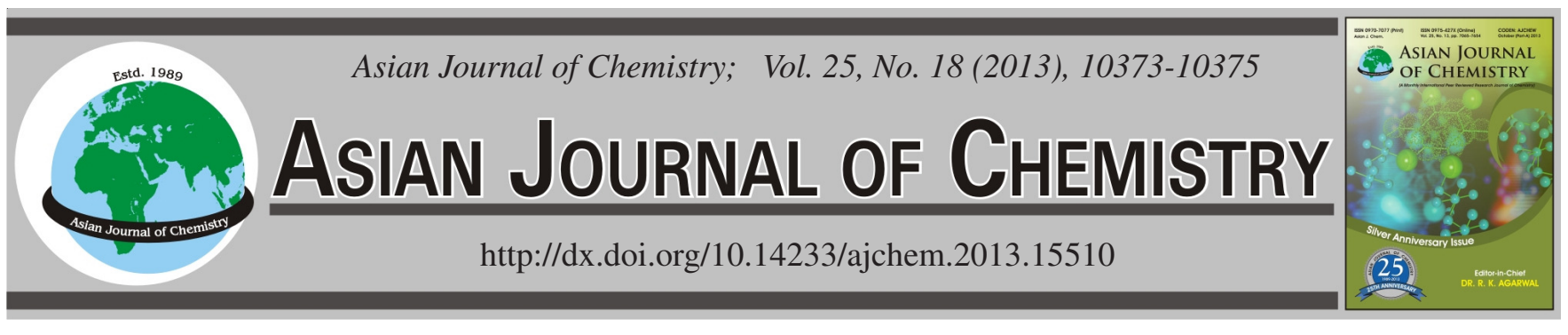

\title{
Spectrophotometric Determination of Micro Germanium(IV) with 5-(4-Carboxylphenylazo)-8-hydroxylquinoline as Colour Reagent
}

\author{
QIU-JIANG Du ${ }^{1, *}$ and WEN-BIN CHEN ${ }^{2}$
}

${ }^{1}$ School of Pharmaceutical and Chemical Engineering, Lianyungang Technical College, Lianyungang 222006, Jiangsu Province, P.R. China ${ }^{2}$ Department of Chemical Engineering Huaihai Institute of Technology, Lianyungang 222005, P.R. China

*Corresponding author: E-mail: dulaoshi163@163.com

(Received: 20 March 2013;

Accepted: 14 November 2013)

AJC-14406

\begin{abstract}
The colour reaction of chromogenic agent 5-(4-carboxylphenylazo)-8-hydroxylquinoline with Ge(IV) was studied in the presence of micromulsion CTMAB-OP. A novel spectrophotometric determination of trace Ge(IV) with high sensitivity was established. The results showed that in the $\mathrm{Na}_{2} \mathrm{~B}_{4} \mathrm{O}_{7}-\mathrm{NaOH}$ medium of $\mathrm{pH}$ 9.8, 5-(4-carboxylphenylazo)-8-hydroxylquinoline reacted with $\mathrm{Ge}$ (IV) could form a red stable complex and the molar ratio of reagent:metal was 3:1. The maximum absorption peak of the complex was located at $558 \mathrm{~nm}$ with the apparent molar absorptivity of $2.5 \times 10^{5} \mathrm{~L} \mathrm{~mol}^{-1} \mathrm{~cm}^{-1}$. In $10 \mathrm{~mL}$ of solution, 0.03-2.8 $\mu \mathrm{g}$ of Ge(IV) obeyed Beer's law and the detection limit was $0.1 \mathrm{mg} / \mathrm{L}$. The colour reaction system could tolerate many interfering ions due to the existence of ammonia. This method was applied to determination of trace Ge(IV) in tea. The results are in consistency with the results obtained by atomic absorption spectrometric method. Recovery was also tested and values obtained were in the range of $102.5-103.6 \%$ and the RSD $(n=6)$ of lower than $3.6 \%$
\end{abstract}

Key Words: 5-(4-Carboxylphenylazo)-8-hydmxylquinoline, Spectrophotometric method, Ge(IV).

\section{INTRODUCTION}

The trace element Ge(IV) with physiological functions of anticancer, antiaging, improving the body's immunity has been used more and more in many areas,such as in medicine, clinical medicine, food health products, etc. So studies on the methods of determining Ge (IV) are of realistic sense. There are many methods for determination of germanium, such as atomic absorption spectrometry (AAS) ${ }^{1}$, atomic emission spectrometry ${ }^{2}$, polarographic analysis ${ }^{3}$, inductively coupled plasma mass (ICP-MS) ${ }^{4}$, spectrofluorimetry ${ }^{5}$ and spectrophotometry . Now there have been some methods for the spectrophotometric determination of germanium such as rhodanine ${ }^{6}$, porphyrin ${ }^{7}$, fluorone ${ }^{8}$, etc. The electron cloud structure changes its chromophore, make the colour change, determination of carboxyazo reagents have been used in copper, lead ${ }^{9,10}$ and other heavy metal ions, but has not been reported for determination of Ge(IV). 5-(4-Carboxylphenylazo)-8-hydroxylquinoline has been used to determine the trace amount of mercury(II) and platinum(II). It was found that Ge(IV) could react with the reagent 5-(4-carboxylphenylazo)-8-hydroxylquinoline to form a stable blue complex (1:3) in $\mathrm{pH}$ range of 9.5-10.5, in the presence of hexadecyl trimethyl ammonium bromide, which has the maximum adsorption peak at $558 \mathrm{~nm}$ with an apparent molar adsorptivity of $\varepsilon_{558} 2.5 \times 10^{5} \mathrm{~mol}^{-1} \mathrm{~cm}^{-1}$. Beer's law is obeyed at the Ge(IV) concentration range of 0.01-2.8 $\mu \mathrm{g} / 10$ $\mathrm{mL}$. Moreover, this colour system has excellent selectivity and stability. Most of the metal ions can be tolerated in considerable amounts without any masking reagents, especially large amounts of Mo and $\mathrm{W}$ which do not interfere with determination of trace germanium. Its selectivity was superior to other congener reagents. The proposed method is simple, fast and selective and has been applied to the determination of trace amount of germanium in tea and zinc concentrate samples with satisfactory results.

\section{EXPERIMENTAL}

UNICO WFJ 7200 spectrophotometer (Shanghai Analytical Instrument Factory V); pH-3C pH meter (Shanghai Precision kore Magnetic Co., Ltd.). Borax- $\mathrm{NaOH}\left(\mathrm{Na}_{2} \mathrm{~B}_{4} \mathrm{O}_{7^{-}}\right.$ $\mathrm{NaOH}$ ) buffer solution: $\mathrm{pH} 9.80,0.05 \mathrm{~mol} / \mathrm{L}$ of $\mathrm{Na}_{2} \mathrm{~B}_{4} \mathrm{O}_{7}$ solution with $200 \mathrm{~g} / \mathrm{L} \mathrm{NaOH}$ solution tune to the required value in $\mathrm{pH}$ meter; 5-(4-carboxylphenylazo)-8-hydroxylquinoline solution: Weighed $0.05 \mathrm{~g}$ colour reagent, dissolved with ethanol into $100 \mathrm{~mL}$ volumetric flask, diluted with ethanol to scale and shake. Its concentration was $1.6 \times 10^{-3} \mathrm{~mol} / \mathrm{L}$. A standard stock solution of $\mathrm{Ge}(\mathrm{IV})\left(1 \mathrm{mg} \mathrm{mL}^{-1}\right)$ was prepared as follow: weigh metal Ge $0.1 \mathrm{~g}$ in $250 \mathrm{~mL}$ beaker, add $(1+4)$ 
$\mathrm{H}_{2} \mathrm{O}_{2}$ 20-30 mL, heating it in the water bath solution (dropping a few drops of $\mathrm{NH}_{3} \cdot \mathrm{H}_{2} \mathrm{O}$ can accelerate decomposition). Adding a few $\mathrm{mL}$ of hot water, using $(1+1)$ dilute $\mathrm{HCl}$ to acidify it and excessive $2-3 \mathrm{~mL}$, boiled to drive hydrogen peroxide out, cooling, then transferred into $1000 \mathrm{~mL}$ calibrated flask, diluted with water to calibration, shaking. Then diluted the solution with distilled water to the concentration of $1 \mu \mathrm{g} /$ $\mathrm{mL} ; 5 \mathrm{~g} / \mathrm{L}$ solution of hexadecyl trimethyl ammonium bromide (CTMAB) was used in the determination of germanium.

Reagents all above were of analytical grade, water used in the test was double distilled water.

Methods: $1 \mu \mathrm{g}$ of Ge(IV) was transferred into a $10 \mathrm{~mL}$ calibrated flask, $1.5 \mathrm{~mL} \mathrm{pH} 9.80$ of buffer solution, $1.2 \mathrm{~mL}$ of CTMAB solution and $1.5 \mathrm{~mL}$ of 5-(4-carboxylphenylazo)-8hydroxylquinoline were added successively. Then it was diluted to the mark with water and mixed well and stood for $15 \mathrm{~min}$. The absorbance of the coloured solution was measured at 558 $\mathrm{nm}$ in a $1 \mathrm{~cm}$ path length against a blank reagent solution.

\section{RESULTS AND DISCUSSION}

Absorption curve: The absorption spectra of the reagent 5-(4-carboxylphenylazo)-8-hydroxylquinoline (CPAHQD) and Ge(IV)-CPAHQD complex were shown in Fig. 1. It was evident that the maximum absorption of CPAHQD was at 490 nm while the Ge(IV)-CPAHQD and Ge(IV)-CPAHQDCTMAB complex were separate at 550 and $558 \mathrm{~nm}$. The contrast of the two peaks was $68 \mathrm{~nm}$, which can be obviously distinguished. So the absorption peak $558 \mathrm{~nm}$ was chosen as the determination wavelength.

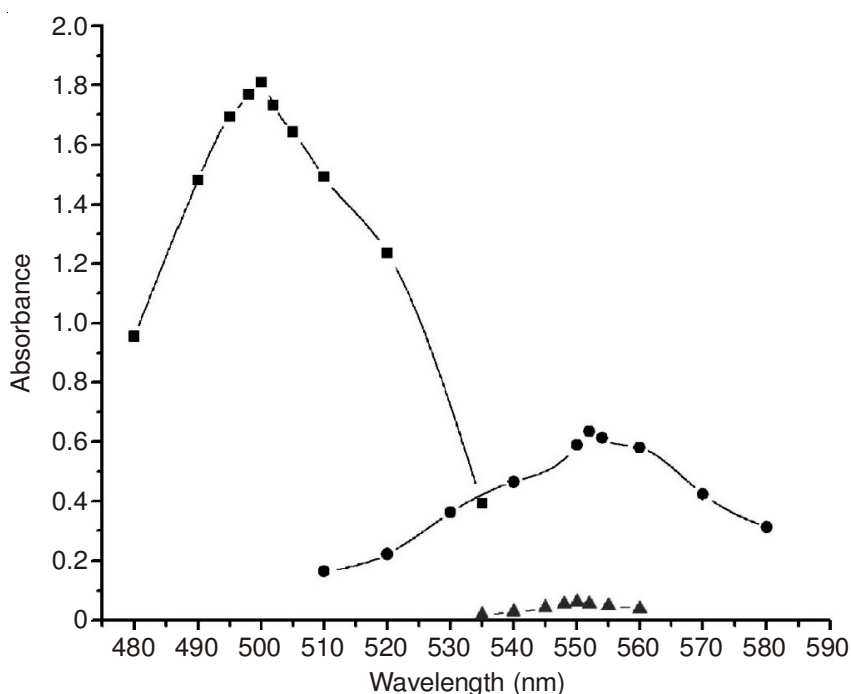

Fig. 1. Absorption spectra. 1. Reagent blank/water, 2. Ge(IV)-CPAHQDCTMAB/reagent blank. 3. Ge(IV)-CPAHQD/reagent blank

Effect of system acidity: A series of solution with different values of $\mathrm{pH}$ were prepared to determine the influence of $\mathrm{pH}$ solutions ( $\mathrm{HCl}, \mathrm{H}_{2} \mathrm{SO}_{4}, \mathrm{H}_{3} \mathrm{PO}_{4}, \mathrm{Na}_{2} \mathrm{SO}_{3}, \mathrm{NaOH}, \mathrm{AcOH}-\mathrm{NaOAc}$, $\left.\mathrm{H}_{3} \mathrm{BO}_{3}-\mathrm{NaOH}, \mathrm{NH}_{3} \cdot \mathrm{H}_{2} \mathrm{O}-\mathrm{NH}_{4} \mathrm{Cl}, \mathrm{Na}_{2} \mathrm{~B}_{4} \mathrm{O}_{7}-\mathrm{HCl}, \mathrm{Na}_{2} \mathrm{~B}_{4} \mathrm{O}_{7}-\mathrm{NaOH}\right)$ on the absorbance of the complex. Results show that the complex was almost unchanged in the $\mathrm{pH}$ range of 9.5-10.5, therefore the buffer solution of $\mathrm{Na}_{2} \mathrm{~B}_{4} \mathrm{O}_{7}-\mathrm{NaOH}$ with $\mathrm{pH} 9.80$ was selected. In the range of 1.0-1.8 mL, the absorbance of the complex was largest and kept constant. In this study, $1.5 \mathrm{~mL}$ was chosen as the reactive dose.
Influence of the colour reagent dosage: With the increase of the volume of CPAHQD solution, the absorbance increased rapidly, followed by remaining almost at a maximum and unchanged. the addition of 1.2-1.8 mL solution gave maximum and constant absorbance, thus an addition of $1.5 \mathrm{~mL}$ CPAHQD solution was recommended.

Surfactant types and the choice of the amount: After investigated different types of surfactants on the impact of the colour system, it was found that in the presence of 1.0-1.6 mL CTMAB the system gave the maximum and constant absorbance, thus an addition of $1.2 \mathrm{~mL}$ was recommended.

Influence of reagent adding order and colour reaction time and the stability of complex: Various adding order of reagents will affect the colour reaction. The results showed that the adding order of reagents according to the experimental method was the best. The system could finish colour reaction completely in $15 \mathrm{~min}$ at room temperature and stay stability for $7 \mathrm{~h}$.

Determination of complex components: Molar ratio method and continuous change method determined the composition of complex was $n(\mathrm{Ge}(\mathrm{IV}): \mathrm{n}(\mathrm{CPAHQD})=1: 3$ as shown in Figs. 2 and 3.

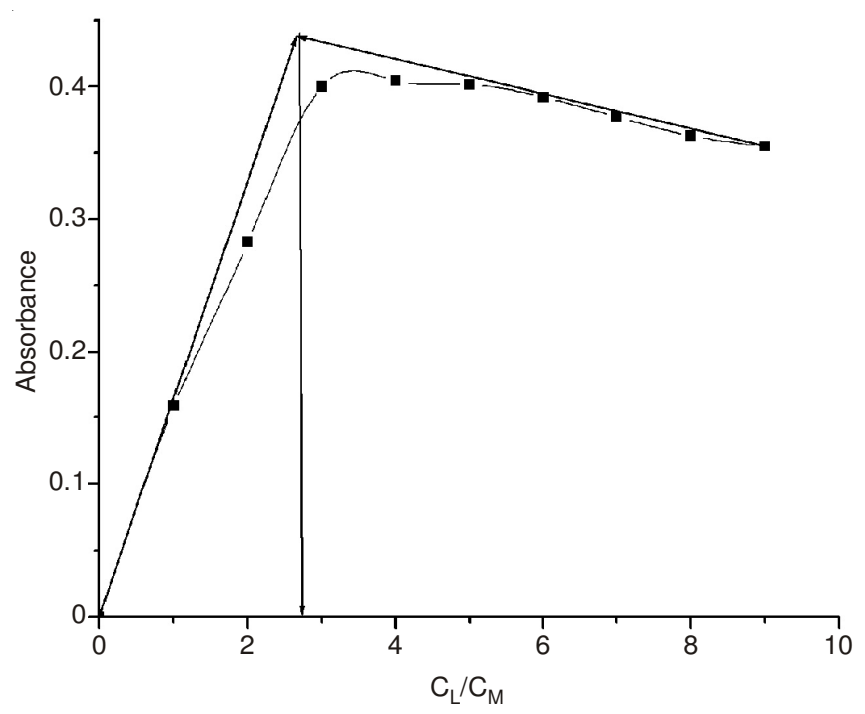

Fig. 2. Molar ratio method

Influence of coexisting ions: Measuring $1 \mathrm{mg} \mathrm{Ge}(\mathrm{IV})$ according to the experimental method, when the relative error is not more than $5 \%$, the maximum amount $(\mathrm{mg})$ of coexistent ions was permitted as follows $\mathrm{K}^{+}(30000) ; \mathrm{Na}^{+}(25000)$; $\mathrm{Ca}^{2+}$ (1000); $\mathrm{Mg}^{2+}(800) ; \mathrm{Ba}^{2+}(500) ; \mathrm{Al}^{3+}$ (300); $\mathrm{Ni}^{2+}$ (250); $\mathrm{Cd}^{2+}(200)$; $\mathrm{Cr}(\mathrm{VII}), \mathrm{Co}^{2+}(150) ; \mathrm{Pb}^{2+}(120) ; \mathrm{Pd}^{2+}, \mathrm{Bi}^{3+}(100)$; $\mathrm{Mn}^{2+}(80) ; \mathrm{Bi}^{3+}(50) ; \mathrm{Fe}^{3+}, \mathrm{Pt}^{2+}(40) ; \mathrm{Rh}^{3+}(10), \mathrm{Zn}^{2+}$, (18) $\mathrm{Sr}^{2+}$; $\mathrm{In}^{3+}(35) ; \mathrm{Sb}^{3+}(30) ; \mathrm{Mo}^{6+}, \mathrm{Ti}(\mathrm{IV})(25) ; \mathrm{Au}^{3+}, \mathrm{Ag}^{+}(20) ; \mathrm{Os}(\mathrm{III})$, $\mathrm{Zr}(\mathrm{IV})(15) ; \mathrm{W}^{3+}(10) ; \mathrm{Sn}^{4+}(5) ; \mathrm{Ru}^{3+}, \mathrm{Ga}^{3+}(3) ; \mathrm{V}(\mathrm{V}), \mathrm{Hg}^{2+}(2)$; $\mathrm{Nb}(\mathrm{V}), \mathrm{La}^{3+}, \mathrm{Cu}^{2+}(1)$; triethanolamine (2000) tartrate (1500) citrate (1000). Lots of EDTA can exist, EDTA can be use as the masking reagents improve other ions coexistent amount. $\mathrm{SO}_{4}{ }^{2-}, \mathrm{PO}_{4}{ }^{3-}, \mathrm{NO}_{3}^{-}, \mathrm{NO}_{2}{ }^{-}$have no influence on the determination of $\mathrm{Ge}(\mathrm{IV})$. Experimental results showed that interference of $0.25 \mathrm{mg} \mathrm{Cu}^{2+}, 0.2 \mathrm{mg} \mathrm{Fe}^{3+}, 0.3 \mathrm{mg} \mathrm{Hg}^{2+}$ could be eliminated efficiently by addition of $05 \mathrm{~mL} 2 \mathrm{~g} / \mathrm{L}$ EDTA. For the sample 


\begin{tabular}{ccccccc}
\hline \multicolumn{7}{c}{ TABLE-1 } \\
\multicolumn{7}{c}{ DETERMINATION RESULTS OF GERMANIUM(IV) IN TEA SAMPLE $(\mathrm{n}=6)$} \\
\hline Sample & Recommend $(\mu \mathrm{g} / \mathrm{L})$ & Method $(\mu \mathrm{g} / \mathrm{L})$ & Average $(\mu \mathrm{g} / \mathrm{L})$ & RSD $(\%)$ & Added Ge $(\mathrm{IV})(\mu \mathrm{g})$ & Recovery $(\%)$ \\
\hline Tea-1 & $6-25$ & $6.22,6.23,6.24,6.21,6.23,6.24$ & 6.23 & 1.80 & 1 & 102.5 \\
Tea-2 & $5-30$ & $5.27,5.28,5.28,5.29,5.31,5.32$ & 5.29 & 3.60 & 1 & 103.6 \\
\hline
\end{tabular}

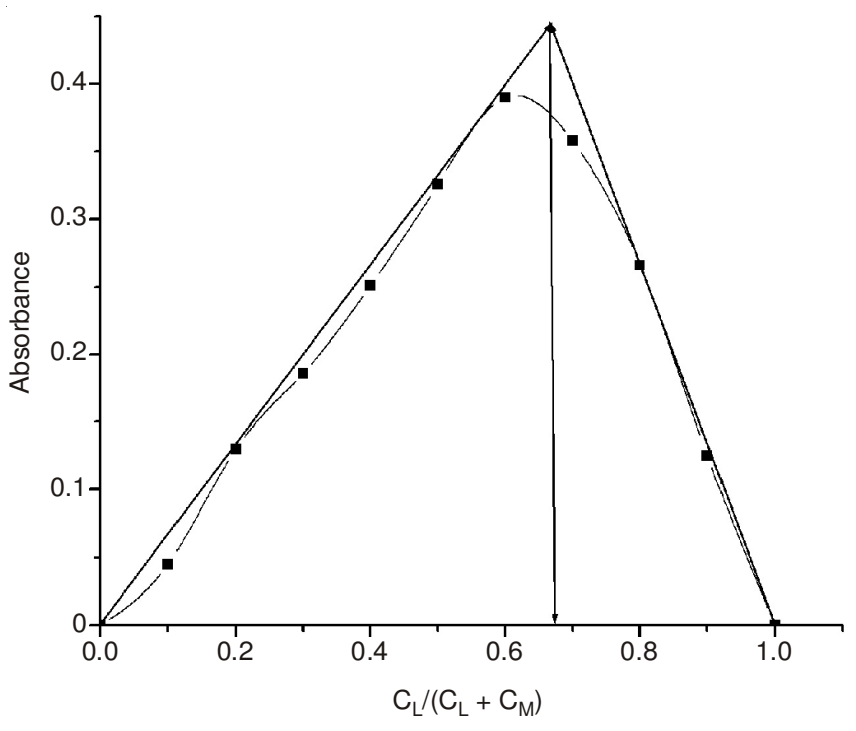

Fig. 3. Continuous change method

which contain more interferential ions (such as znic concentrate which contains lots of $\mathrm{Zn}^{2+}$ ), we can use DDTC/CCl $\mathrm{Cl}_{4}$ extraction and water antiextraction, then determine by experimental methods.

Calibration curve and sensitivity: Adding a quantity of standard Ge(IV) working solution in a series of $10 \mathrm{~mL}$ calibrated flask, do the colour reaction etermination according to the experimental methods, when the quantity of Ge is from 0.03 $2.8 \mathrm{mg}$, it obey the Beers law. The linear regression equation is: $A=0.3600 \rho(\mu \mathrm{g} / 10 \mathrm{~mL})+0.0015$ with a correlation coefficient of 0.9999 . The apparent molar absorptivity is $2.5 \times 10^{5}$ $\mathrm{L} \mathrm{mol}^{-1} \mathrm{~cm}^{-1}$ and method detection limit was $0.01 \mathrm{mg} / 10 \mathrm{~mL}$.
Sample analysis: Take a certain amount of tea in the oven, dry at $1000^{\circ} \mathrm{C}$, ground, weighed $1 \mathrm{~g}$ sample in $100 \mathrm{~mL}$ conical bottle. Added $10 \mathrm{~mL}$ conc. $\mathrm{HNO}_{3}$, after $2 \mathrm{~h}$, heating at low temperature in distillation unit, circufluence and digest until solution clarified, remove the distillation, heating to volatile nitrate. When the solution remains 1-2 $\mathrm{mL}$, add $\mathrm{H}_{2} \mathrm{O}_{2}$ by drop, when the solution is colourless, stop dropping, continue to heat until completely dry and cold to room temperature. After adding appropriate distilled water dissolve solids, add $15 \mathrm{~mL}$ $9 \mathrm{~mol} \mathrm{~L}^{-1} \mathrm{HCl}$, shake and add $10 \mathrm{~mL} \mathrm{CCl}_{4}$, oscillating $5 \mathrm{~min}$ and extraction, static delamination and separate $\mathrm{CCl}_{4}$ in another funnels, add $10 \mathrm{~mL}$ of water and extraction after transfer to $25 \mathrm{~mL}$ calibrated flask, constant volume and shake, fetch $2 \mathrm{~mL}$ solution, determine by the experimental methods, the results were shown in Table-1.

\section{Conclusion}

The method has been used for the determination of trace germanium(IV) in tea with satisfactory results and the result was in accordance with that of the atomic absorption spectrometry method.

\section{REFERENCES}

1. M.A. Anwari, H.U. Abbasi, M. Volkan and O.Y. Ataman, Fresenius' J. Anal. Chem., 355, 284 (1996).

2. R.S. Braman and M.A. Tompkins, Anal. Chem., 50, 1088 (2005).

3. C. Schleich and G. Henze, Fresenius' J. Anal. Chem., 338, 145(1990).

4. R.A. Mortlocka and P.N. Froelich, Anal. Chim. Acta, 332, 227 (1996).

5. A.M. Garcia-Campaña, F.A. Barrero, A. Lupiáñez-González, M. Román-Ceba, Anal. Chim. Acta, 447, 219 (2001).

6. X.-W. He, S.-W. Bi and H. Wang, J. Anal. Sci., 298, 21 (2005).

7. W.B. Chen, X.-Y. Xu and W.-X. Ma, Chin. J. Anal. Lab., 6, 24 (2005).

8. B.-H. Li, G.-H. Wang and J.-X. Jia, Chem. Res. Appl., 242, 14 (2002).

9. G.-S. Ye and H.-W. Gao, J. Anhui Univ. Nat. Sci. Ed.., 90, 24 (2000).

10. G.-F. Li, H. Liang and Q.-X. Liu, Metallurgical Anal., 23, 18 (1998). 